\title{
REAVI
}

\section{PAPÉIS DA PERÍCIA CRIMINAL CONTÁBIL E CONTABILIDADE FORENSE: DIFERENÇAS E ESTUDO BILBIOMÉTRICO}

\section{ROLES OF CRIMINAL ACCOUNTING AND FORENSIC ACCOUNTING: DIFFERENCES AND BILBIOMETRIC STUDY}

\author{
Bruna Benita Weber Sanchez Lopez* \\ Sérgio Murilo Petri**
}

\section{RESUMO}

Diante de cenários no Brasil e no mundo, com escândalos de corrupção em empresas e órgãos públicos, tornou-se necessário medidas para detectar e impedir fraudes, assim como a geração de provas para os órgãos julgadores. Visto a relevância, este trabalho tem por objetivo evidenciar e diferenciar os papéis da perícia criminal contábil e da contabilidade forense, a partir das análises bibliométricas dos artigos publicados sobre os referidos temas no período de 1999 até 2019. Para o subsídio da pesquisa bibliométrica, fez uso das bases Spell, Scielo e Google Acadêmico em uma abordagem quali-quanti, a fim de apresentar dados da arte da produção científica realizada nos últimos anos sobre a temática, que é tão relevante para a justiça em sociedade. Foram encontrados 20 artigos, número inferior frente a importância do tema. A pesquisa demonstrou que são poucos autores que se aprofundam no tema com trabalhos publicados e existem semelhanças e diferenças entre Perícia Criminal e Contabilidade Forense, sendo que ambas as áreas visam a resolução de conflitos e utilizam-se da ciência em favor de esclarecimentos de fatos e da verdade, com senso crítico, olhar cético, conhecimento aprofundado sobre contabilidade, aspectos jurídicos e graus de expertise, já as principais diferenças estão nos órgãos que determinam os trabalhos, assim como a regularização e a formação dos profissionais.

Palavras-chave: Fraude. Perícia Criminal Contábil. Contabilidade Forense.

\begin{abstract}
Faced with scenarios in Brazil and in the world, with corruption scandals in companies and public bodies, measures to detect and prevent fraud, as well as the generation of evidence for the judging bodies, became necessary. Given the relevance, this work aims to highlight and differentiate the roles of criminal accounting expertise and forensic accounting, based on bibliometric analyzes of articles published on the referred topics in the period from 1999 to 2019. For the subsidy of bibliometric research, he did use of the Spell, Scielo and Google Scholar bases in a quali-quanti approach, in order to present data from the art of scientific production carried out in recent years on the topic, which is so relevant to justice in society. Twenty articles were found, a lower number due to the importance of the topic. It was concluded that there are few authors who delve into the theme with published works and there are similarities and differences between Criminal Expertise and Forensic Accounting, both areas aiming at conflict resolution and using science in favor of clarifying facts and from the truth, with a critical sense, a skeptical eye, in-depth knowledge of accounting, legal aspects and degrees of expertise, the main differences are in the bodies that determine the jobs, as well as the regularization and training of professionals.
\end{abstract}

Keywords: Fraud. Accounting Criminal Expertise. Forensic Accounting.

\footnotetext{
*UFSC - Universidade do Estado de Santa Catarina. E-mail: xbrune13@gmail.com

** UFSC - Universidade do Estado de Santa Catarina. E-mail: smpetri@ gmail.com

Revista Eletrônica do Alto Vale do Itajaí - REAVI, v.09, n 15, p. 077-095, dez. 2020. ISSN: 2316-

4190, DOI 10.5965/2316419009152020077
} 


\section{REAVI}

\section{INTRODUÇÃO}

A contabilidade quanto ciência social aplicada, segundo o CPC 00, deve fornecer informações financeiras úteis, relevantes, fidedignos e transparentes sobre os fenômenos econômicos, visando auxiliar os gestores das entidades privadas e públicas (CFC, 2020). Apesar destas responsabilidades, práticas desassociadas à ética e reponsabilidade social são utilizadas por alguns profissionais, na pretenção de obter vantagem na facilitação de lavagem de dinheiro e ocultamento de bens.

Diante de cenários com escândalos de corrupção, em empresas e órgãos públicos, no Brasil e no mundo, tornou-se necessário medidas para detectar e impedir fraudes, assim como a geração de provas para diferentes usuários. Para atender essa necessidade, a profissão contábil, quanto seu papel informacional, ganhou mais ênfase, como um importante instrumento de inteligência frente aos crimes financeiros organizados. De acordo com Silva (2019) "a criminalidade e seu aperfeiçoamento são fatores que preocupam toda a população, e o fortalecimento de práticas e técnicas de prevenção, combate e repressão a tais práticas, são essenciais para a manutenção de segurança para a vida em sociedade". Segundo a Associação Nacional dos peritos criminais Federais (2020), no Brasil há vários exemplos de participações efetivas de peritos criminais contábeis em investigações como do Mensalão, Lava Jato, Caixa de Pandora, Sanguessuga, Zelotes, Greenfield e Bullish, dentre outras, em que a perícia contábil-financeira tem marcado presença em operações de grande repercussão (ROSA; LIMA, 2020).

Nesse contexto, visando restaurar a confiança dos usuários da informação e da justiça, surgiu a contabilidade forense, que investiga possíveis fraudes, que na visão de Grippo e Ibex (2003, p. 10) é "a ciência que lida com fatos contábeis reunidos por meio de métodos de procedimentos de auditoria aplicados a problemas de ordem legal”. Já a perícia criminal contábil, de acordo com Silva (2019) tem o papel de "elucidar os crimes que ocasionam o maior prejuízo para a sociedade, àqueles que envolvem sonegação, desvio ou ocultação de dinheiro, que deveriam ir ao encontro do interesse público e da efetivação de políticas públicas", desse modo, trazem a veracidade de fatos levados a questionamento por crimes financeiros. Diante do exposto, entende-se que ambas as áreas visam a resolução de conflitos e utilizam-se da ciência em favor de esclarecimentos de fatos e da verdade, com isso, questiona-se, como a perícia criminal contábil e a contabilidade Forense estão sendo tratadas na literatura brasileira?

Por isso, a fim de responder a problemática, este trabalho tem por objetivo evidenciar os papeis da perícia criminal contábil e da contabilidade forense, a partir das análises bibliométricas dos artigos publicados sobre os referidos temas no período de 1999 até 2019, já que, por envolver conteúdo de sigilo judicial, as atividades periciais são pouco conhecidas pela sociedade e inclusive entre os acadêmicos de contabilidade (WEBER; FLACH; LAFFIN, 2018).

\section{REVISÃO DA LITERATURA}

A presente sessão tem o propósito de fornecer fundamentação teórica ao trabalho, bem como identificar o estágio atual do conhecimento de determinado tema (SOARES; PICOLLI; CASAGRANDE, 2018) com a contextualização dos cenários da Perícia Criminal Contábil e da Contabilidade Forense, visando trazer conceitos que possam esclarecer distinções da Perícia Criminal Contábil com a Perícia Contábil, Contabilidade Forense e Auditoria, com o propósito de elucidar perspectivas sobre essas áreas que prometem ser promissoras para os profissionais da contabilidade.

Revista Eletrônica do Alto Vale do Itajaí - REAVI, v.09, nº 15, p. 077-095, dez. 2020. ISSN: 23164190, DOI 10.5965/2316419009152020077 


\section{REAVI}

\subsection{PERÍCIA CRIMINAL CONTÁBIL}

Abraçando a contabilidade como a ciência responsável pelo registro e controle do patrimônio, o perito criminal contábil tem o importante papel de elucidar os crimes "que envolvem sonegação, desvio ou ocultação de dinheiro, que deveriam ir ao encontro do interesse público e da efetivação de políticas públicas", sendo assim, os casos em que o delito deixar vestígios, deverá ser aplicado o Código de Processo Penal, sendo taxativo quanto à necessidade de perícia criminal. Dessa maneira, a perícia criminal contábil "ocupa lugar central nos processos que envolvem crimes contra o sistema financeiro ou contra a ordem econômica e tributária" (SILVA, 2019). Nesse mesmo pensamento, a Associação Nacional de Peritos Criminais Federais (2020), afirmam que em cenários de repressão financeira, destaca-se a prova pericial contábil, que diferentemente das cenas de crimes de homicídio, os crimes de natureza econômica deixam vestígios espalhados em estruturas financeiras, econômicas e administrativas, como em extratos bancários, cheques, ordens bancárias, relatórios de aplicações financeiras, declarações de impostos de renda, processos licitatórios, contratos, notas fiscais, livros contábeis e diversos outros documentos que representem as transações e as relações econômicas. Assim, a análise pericial se torna crucial no apontamento na existencia ou não de tais crimes caracterizadores (ROSA; LIMA, 2020).

A exemplo dos crimes citados pela Associação Nacional de Peritos Criminais Federais, o perito criminal pode estar apto tambem na identificação de desvios de recursos públicos e corrupção, onde há pagamentos indevidos, contratos fraudulentos, notas fiscais frias e calçadas, sobrepreço ou superfaturamento de produtos e serviços. Assim, durante a identificação das atividades ilícitas, diversas estratégias são usadas, a exemplo da lavagem de dinheiro, se identifica o fracionamento de recursos, circulação de dinheiro por paraísos fiscais, ocultação de valores e patrimônio, o emprego de "laranjas" e "testas de ferro", a contabilidade fraudulenta ou paralela, a simulação de renda, a simulação de operações comerciais e os empréstimos fictícios, sendo indispensável o rastreamento de recursos, que identificam a origem e o destino de fundos movimentados, a fim de desenhar o caminhos traçados e alcançar a conexão do crime antecedente. Dentro de outros instrumentos se destaca também a Declaração de Ajuste Anual do imposto de renda Pessoa Física, que se tratando de informações falsas declaradas pelos criminosos é capaz de confrontar as informações com documentos que as confirmem ou revelem a ficção, e assim, aponta-las como meio de promoção de lavagem de dinheiro (ROSA; LIMA 2020).

Desse modo, a perícia criminal contábil é em casos de crimes com vestígios, uma elucidação de fatos em julgamentos, sendo um importante instrumento a justiça, com influência nas decisões judiciais, já que, o juiz, diante de uma situação em que abrange conhecimentos que são inerentes a seus conhecimentos, busca auxílio na resolução de questões financeiras e patrimoniais para interpretar as provas e traduzi-las de um modo que possa ter um posicionamento sobre tais questionamentos (SILVEIRA et., al, 2013).

Ademais, a perícia criminal contábil, por apresentar crimes com aspectos contábeis abrange grande quantidade de dinheiro público, e, portanto, o laudo se torna um importante instrumento de responsabilização aos criminosos. Por isso, é um serviço realizado pelo próprio estado, sendo requisitado pelo "magistrado, pelo ministério público ou pela autoridade policial aos Institutos de Criminalística ou órgãos semelhantes, e executadas no âmbito dos Estados e do Distrito Federal, pelas polícias civis ou polícias técnico-científicas e, no âmbito nacional, pela polícia federal" (JUNIOR, 2011).

Revista Eletrônica do Alto Vale do Itajaí - REAVI, v.09, nº 15, p. 077-095, dez. 2020. ISSN: 23164190, DOI 10.5965/2316419009152020077 


\section{REAVI}

Quanto a atuação do perito criminal, Passini e Pereira (2018) tambem alegam que "enquanto o perito da perícia contábil cível é profissional independente, sendo indicado/solicitado pelos magistrados ou partes, o perito criminal faz parte do quadro de servidores do estado, atuando em busca da solução de litígios de interesse público", portanto, uma das principais diferenças quanto a contabilidade forense são encontradas frente aos órgãos determinantes dos trabalhos.

Dessa forma, entende-se que a realização das pericias criminais contábeis, são exercidos por "peritos criminais oficiais designados para os trabalhos pelos dirigentes de criminalística", ou, por dois peritos ad hoc, na ausência desses profissionais, conforme indica o artigo 159 do Código de Processo Penal, com redação dada pela Lei 11.690 de 2008, portador de curso superior, preferencialmente na área específica, dentre as que tiverem habilitação técnica relacionada com a natureza do exame para atender o compromisso (BRASIL, 2008).

Diferente dos demais tipos de perícia, a perícia criminal obedece a um conjunto de regras próprios, inerentes ao direito penal, e, se encontra vinculada tambem, às regulamentações advindas dos conselhos de classe.

Nessa linha, os responsáveis dos trabalhos de perícia criminal contábil no Brasil, é explicado por Neves Júnior e Moreira (2011, p. 133):

\footnotetext{
Diferentemente da Perícia Contábil Judicial, determinada pelo magistrado, a Perícia Criminal Contábil é exercida pelo aparelho estatal e determinada pelas autoridades policiais dos Institutos de Criminalística. Nos âmbitos estaduais são executadas pelas polícias civis dos Estados e Distrito Federal; no âmbito nacional, pelo Instituto Nacional de Criminalística do Departamento de Polícia Federal.
}

Analogamente, o sistema pericial, ou sistema de criminalística é composto por órgãos de apoio ao sistema judiciário, vinculadas em âmbito estadual às Secretarias de Segurança Pública ou em âmbito federal presente na estrutura da Polícia Federal, cujos objetivos são "a produção de provas técnico-científicas que subsidiarão a investigação policial e o processo penal”(LIMA; GONÇALVES, 2018).

O órgão responsável pela realização de perícias criminais no estado é o Instituto Geral de Perícias (IGP), por meio do Instituto de Criminalística no Departamento Técnico Científico Forense, a qual é subordinado diretamente à Secretaria de Segurança Pública. Tem como função coordenar as atividades desenvolvidas pelas perícias criminais do estado por meio dos seus respectivos órgãos (WEBER; FLACH; LAFFIN, 2018). Os autores tambem evidenciaram as principais ilegalidades identificadas no IGP- SC que foram a apropriação indébita, peculato, improbidade administrativa, sonegação fiscal e superfaturamento, que envolvem patrimônio público ou privado e crimes organizados.

O Sistema Nacional de Criminalística da Polícia Federal segundo a Associação Brasileira dos Peritos Criminais Federais:

[..] registra mais de 240 peritos criminais federais da área contábilfinanceira, profissionais com formação acadêmica em ciências contábeis e economia. Destes, cerca de 40 emprestam sua experiência e conhecimento a outros setores da Polícia Federal, especialmente nas áreas de gestão e direção. Os demais estão espalhados pelo País, nas diversas unidades descentralizadas da Polícia Federal, alguns deles lotados em Brasília, no Instituto Nacional de Criminalística, órgão central das perícias criminais da PF (ROSA; LIMA, 2020).

Quando se trata de crimes contábeis financeiros de grande repercussão nacional,

Revista Eletrônica do Alto Vale do Itajaí - REAVI, v.09, n 15, p. 077-095, dez. 2020. ISSN: 23164190, DOI 10.5965/2316419009152020077 


\section{REAVI}

segundo Filhos, Carlo e Costa (2017) a responsabilidade pertence ao sistema de criminalística da Polícia Federal, previstas no artigo 144 da Constituição Federal e possui um corpo técnico de investigação a fraude. Esse sistema é formado pelo Instituto Nacional de Criminalística, localizado em Brasília, por 26 Setores Técnico-Científicos, localizados nas capitais dos Estados e no Distrito Federal, por três Núcleos Técnico-Científicos, sediados em Foz do Iguaçu/PR, Santos/SP e Campinas/SP, e por 22 Unidades Técnico-Científicas espalhadas pelo país (LIMA; GONÇALVES, 2018).

Quanto à requisição, "a perícia criminal costuma ser realizada em momento anterior à fase processual, no âmbito da investigação criminal, fato explicável pela efemeridade dos vestígios e pelo dispositivo legal 158 do CPP, que incube à autoridade policial a requisição da perícia que deixar vestígios" (SILVA, 2019). Assim, o perito criminal contábil busca oferecer ao juiz, conclusões técnicas antes do inicio do processo, emprestando ao julgador o conhecimento especializado necessário para a interpretação e entendimentos dos fatos apurados, afim de elucidar, se existe ou não, potencialidade no auferimento quanto as leis penais.

Por conseguinte, determinado a origem do crime e o orgão responsável e o momento da requisição, os peritos farão a preparação do laudo pericial munido de todas as legalidades que a equiparam, descrevendo minuciosamente a dinâmica dos fatos que tomaram em exame e os critérios adotados para responder aos quesitos formulados pelo juiz. Quanto a sua estrutura, deverá observar os itens exigidos na lei n. 13.105/15. O laudo deverá ser elaborado no prazo máximo de dez dias, que poderá ser prorrogado diante da complexidade do exame, conforme artigo 160 do Código de Processo Penal (WEBER; FLACH; LAFFIN, 2018). Assim, sintetizase as etapas da requisição da Perícia criminal contábil na seguinte figura:

Figura 01 - Requisição do perito criminal contábil no Processo

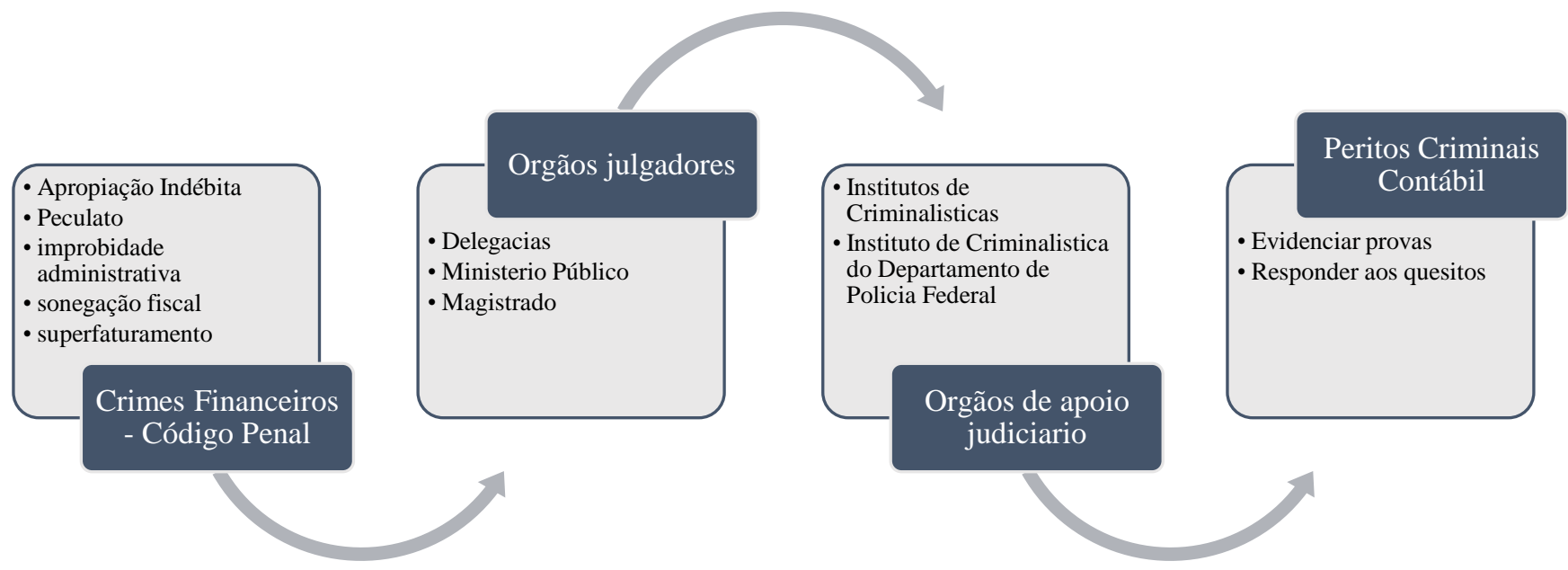

Fonte: adaptado de Weber, Flach e Laffin (2018); Neves Júnior e Moreira (2011).

Referindo-se à tecnologia e sistemas utilizados, a Associação Nacional de Peritos criminais Federais (2020), revela que é uma grande aliada nos desafios do combate a esquemas criminosos. Os peritos dispõem de tecnologia de ponta, com computadores com alta capacidade de processamento e softwares como Qlikview, Suíte I2, Simba e Microsoft Access, que auxiliam no processamento de grandes volumes de dados que contribuem para uma maior eficiência na realização de perícias complexas, tanto em termos de qualidade, quanto em prazo

Revista Eletrônica do Alto Vale do Itajaí - REAVI, v.09, nº 15, p. 077-095, dez. 2020. ISSN: 23164190, DOI 10.5965/2316419009152020077 


\section{REAVI}

de atendimento. Com o sistema "Simba", regulamentado por meio da Instrução Normativa n 42/2010-DG/DPF, os peritos teriam a disposição uma plataforma que permitiria que as instituições financeiras transmitam via rede mundial de computadores, dados bancários de investigados para os órgãos de persecução penal, auxiliando-os diante decisões Judiciais de afastamento de sigilo bancário e suprindo as necessidades das investigações e dos exames periciais (ROSA; LIMA, 2020).

\subsection{CONTABILIDADE FORENSE}

A Contabilidade Forense se tornou a ciência responsável pelo combate à fraude, qualificando-se como "estrutura capaz de produzir provas hábeis e admissíveis em Juízo, implicando o domínio de conhecimentos contábeis, de procedimentos de investigação especiais e multidisciplinares"(CARDOSO, 2008). Analogamente, a Contabilidade Forense é:

[...] uma especialidade da ciência contábil de natureza interdisciplinar, a qual combina conhecimentos da contabilidade, da criminologia, da psicologia, da semiótica, do direito e das finanças, com o objetivo de prevenir e reprimir a fraude e todos os crimes de natureza econômico financeiros, a exemplo da lavagem de capitais (RIBEIRO et.al., 2013, p.2).

No assentimento de Ribeiro (2009), por meio da necessidade de investigar e avaliar processos do mercado financeiro, surge no ambiente inernacional a contabilidade forense. Nesse contexto, o foco do profissional forense estaria centrada na prevenção, detecção e apuração de fraudes. Nas palavras de Silva (2012) o campo de trabalho do contador forense surgiu da necessidade de fortalecer a credibilidade dos auditores e contadores, com habilidades contabeis de investigação e auditoria. Tais conhecimentos auxiliariam "litígios judiciais ou em investigações sobre suspeitas de fraudes e irregularidades, além do rastreamento sobre a origem e o destino de grandes somas, seja em dinheiro ou em outros ativos desviados das entidades" (SILVA, 2012).

Sob o olhar de Ribeiro et., al (2013) os contadores forenses são vistos como uma combinação do profissional auditor e do investigador privado, e suas habilidades estariam centradas na " investigação, pesquisa e levantamento de dados, conhecimentos jurídicos, métodos quantitativos, finanças, auditoria e contabilidade". Dessa forma, o trabalho do contador forense se inicia quando há indício de fraude que precisa ser apurado, indo além da investigação e analisando os impactos que isso pode causar à empresa. Ademais, entende-se portanto que é o ramo da contabilidade que foca na investigação, assim como na Perícia criminal contábil, porém, com conhecimentos de informações de diversas áreas.

A prevenção na contabilidade forense pode envolver medidas de adoção de programas antifraudes de controles internos, sistema de alerta de denúncias irregulares, estabelecer programa continuo de avaliação dos sistemas de risco de fraudes e atos ilícitos. A figura 2 apresenta as habilidades e conhecimentos do contador forense distinguindo-o de outras áreas da contabilidade. 


\section{REAVI}

Figura 2. Habilidades do Contador Forense

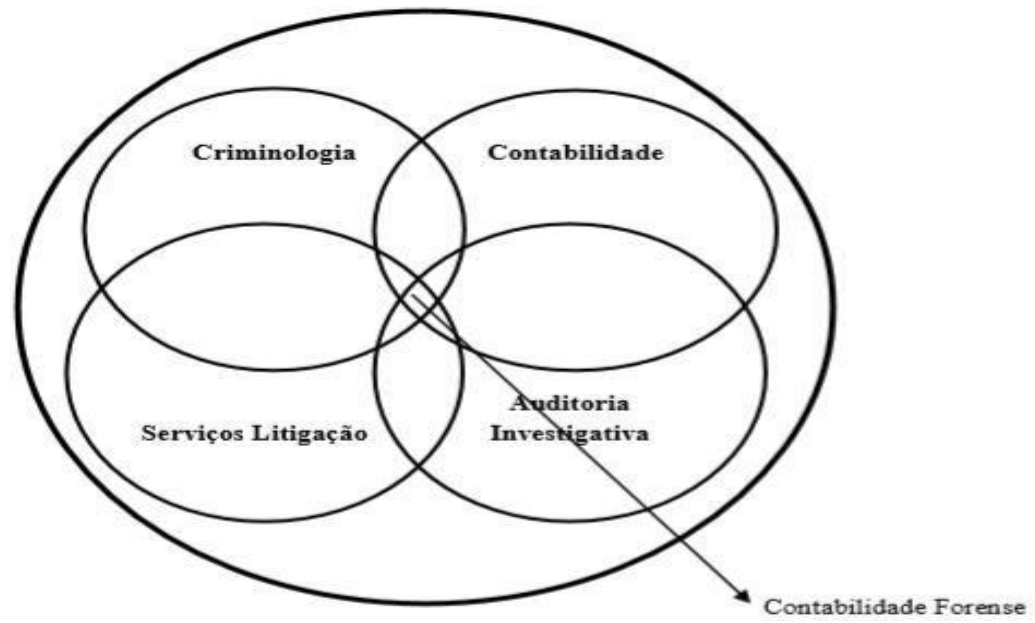

Fonte: Crumbley e Smith (2009).

Observa-se pela figura 1 que o contador forense tem aptidão para entender tanto a área cível como a criminal, em demandas na esfera judicial como privado, atuando tanto como perito como auditor. Sendo assim, a contabilidade forense se determina a encontrar o erro ou a fraude por meio de serviços de investigação, criminologia, técnicas contábeis com a resolução de problemas e serviços de litigação, já a perícia criminal contábil responde por meio do laudo aos questionamentos feitos pelas partes diante de um processo (CRUMBLEY; SMITH, 2005)

A Contabilidade Forense é o instrumento mais amplo e completo na investigação e levantamento de fraudes quando se comparada a atividade de Auditoria (CARDOSO, 2008). Sendo assim, não há que se falar que os termos "Contabilidade Forense" e "Auditoria" se confundem ou são sinônimos. De acordo com Skalak, et. al (2011) o contador forense, possui conhecimento em investigação, resolução de problemas ou suspeitas de fraudes, por meio de análises de documentos, com inclusão de informações financeiras e não financeiras, entrevistas, inquéritos de terceiros, incluindo bancos de dados. Assim, o termo Forense convoca o interesse pela justiça com o direito e aplicação da lei, tornando-se ferramenta de um processo legal, em caráter assistencial ao juiz para resolver disputas legais (SILVA, 2008).

Cabe ressaltar ainda, que pode haver correlação da contabilidade forense com a auditoria no trabalho de prevenção e combate à fraude. Nas palavras de Filho, Costa e Moraes (2017) essa inter-relação é dinâmica e variam assim que acontecimentos sociais, políticos e culturais mudam ao longo do tempo, entretanto, a responsabilidade dos auditores não abrange o planejamento e execução de procedimentos de auditoria para detectar erros que não são considerados significativos, como de fraude. Sendo assim, pode-se então, usar a metodologia da auditoria na Contabilidade Forense, porém, as duas tem finalidades diferentes. A auditoria é um trabalho mais de verificação de adequação as normas, ja que, muitas vezes, o conjunto de habilidades exigidos em uma área é capaz de alavancar as habilidades e capacidades ao trabalhar em outra área (WVU, 2007). 


\section{REAVI}

Tabela 1. Atributos do auditor e do Contador Forense

\begin{tabular}{l|c|c}
\hline & Auditor & Contador Forense \\
\hline Identificação de erro & $\operatorname{sim}$ & \\
\hline Prevenção de erro & $\operatorname{sim}$ & $\operatorname{sim}$ \\
\hline Identificação de fraudes & & $\operatorname{sim}$ \\
\hline Suporte a litígios & & $\operatorname{sim}$ \\
\hline Coleta de evidencias & & $\operatorname{sim}$ \\
\hline Calculo de danos econômicos & & $\operatorname{sim}$ \\
\hline Encontrar fraudador & $\operatorname{sim}$ & $\operatorname{sim}$ \\
\hline Distorção relevante & $\operatorname{sim}$ & \\
\hline Divulgações e procedimentos contábeis & & \\
\hline
\end{tabular}

Fonte: Ahmed e Mohobott (2019).

Nessa linha, tentando distinguir a miscelânea dos conceitos de "auditoria" e "Contabilidade Forense|" conduzidos pela literatura brasileira, Silva (2008) acredita que o termo "Contabilidade Forense" só é descoberto em um cenário de irregularidade, ferindo a lei, e pode ser considerado uma solução contábil-jurídico contra a fraude", para tanto, utiliza-se dos dados financeiros passados para projetar financeiros futuros. Entretanto, as atividades dos auditores envolvem a identificação e prevenção do erro, e podem ter demanda por exigência dos orgãos reguladores como a CVM, por acionistas ou socios de empresas, tendo como produto final o relátorio da auditoria baseado na opinião, ja e os contadores forenses identificam as fraudes, com apuração de fatos, assim como os ferimentos a legislação por requisições de vítimas ou de denúncias e não possui regulamentação por orgãos reguladores, tendo como produto final apenas um relátorio (SILVA, 2008)

Tabela 2. Diferença entre auditoria e Contabilidade Forense

\begin{tabular}{l|l|l}
\hline Tipo & Auditoria & Contabilidade Forense \\
\hline Objetivo & Emitir Opinião & Apurar Fatos \\
\hline Foco & Controle Interno & Processo Judicial \\
\hline Periocidade & Trimestral/Anual & Eventual \\
\hline Demandantes & Órgãos Reguladores, acionistas & Fraudado (Vítimas) \\
\hline Escopo & Demonstrações Financeiras & Denuncia Requerida (ação pena privativa) \\
\hline Produto Final & Relatório de Auditoria & Relatório \\
\hline Tempo & Histórico & Histórico/Futuro \\
\hline Regularização & Regulada pelo NBC e CVM & Não tem regulamentação \\
\hline Tipo & Apuração & Detectivo/Preventivo \\
\hline Formação & & $\begin{array}{l}\text { Múltiplo: Direito, Contabilidade, } \\
\text { Economia, administração, etc. }\end{array}$ \\
\hline
\end{tabular}

Fonte: Adaptada de Silva (2008).

$\mathrm{Na}$ área internacional, a contabilidade forense é denominada pelo termo "Forensic Accounting". Assim, na visão dos contadores internacionais, profissionais forenses identificam os sinais de fraude quando os outros contadores de outras especialidades, como de custos, gerencial ou financeira, tem limitações ao fazê-lo (AHMEDI; MOHOBOTT, 2019). Contadores forenses durante a realização de investigação podem examinar bancos de dados internos e registros judiciais. Os fraudadores costumam ocultar as evidencias dos crimes e os contadores forenses com seu olhar cético devem olhar além dos números para prever ações criminais (AHMEDI; MOHOBOTT, 2019).

Revista Eletrônica do Alto Vale do Itajaí - REAVI, v.09, n 15, p. 077-095, dez. 2020. ISSN: 23164190, DOI 10.5965/2316419009152020077 


\section{REAVI}

As atividades gerais dos contadores forenses podem incluir a análise da situação financeira, considerações de um processo, preparar um relatório de danos e testemunhar como testemunha especializada (AHMEDI; MOHOBOTT, 2019), portanto, a investigação de informações são reunidas a partir de evidências documentais e depoimentos. As evidências abordam questões como quem, o que, quando, onde, como e por que motivo em relação aos suspeitos fraude. Contadores forenses são especialmente designados para trabalho nessas duas áreas - contabilidade investigativa e apoio a litígios. Contabilidade investigativa não se limita apenas a números e documentos de uma empresa, mas a entender os negócios ambiente também (AHMEDI; MOHOBOTT, 2019).

Dessa maneira, entende-se que a contabilidade forense é um campo especializado da contabilidade, que analisa os trabalhos resultantes do litígio para investigar crimes financeiro, com seu olhar cético de práticas contábeis proativas, os profissionais podem identificar os erros e transações desviantes (ABDULRAHMAN, 2020).

Cabe destacar, que durante a pesquisa no ambito internacional, paises como na Espanha, México, Chile, Argentina, entre outros, que são hispano falantes, usam-se do termo "auditoria forense". De acordo com o autor Paniagua (2018) a auditoria Forense é um tipo de auditoria especializada em descobrir, divulgar e atestar sobre fraudes e delitos financeiros. Em termos contábeis, pode-se entender como a ciência que permite reunir e apresentar informação financeira, legal e tem como objetivo a investigação criminal diretamente relacionada com os campos de contabilidade e finanças. Portanto, para esses países, a contabilidade forense é um ramo da auditoria, responsável por elucidar fraudes contábeis e financeiros.

\subsection{DIFERENÇA ENTRE PERÍCIA CONTÁBIL, PERÍCIA CRIMINAL CONTÁBIL E CONTABILIDADE FORENSE}

Como descrito nos topicos anteriores, existem descrições conceituais de pesquisas sobre a finalidade e as caracteristicas dos profissionais em Perícia Contábil, Perícia Criminal Contábil e Contabilidade Forense e, por terem algumas semelhanças, podem gerar confusão aos leitores.

Autores como Lucas e Relvas (2013) destacarm a timida atuação do contador forense no Brasil e a forte semelhança com o perito contador, e com o intuito de identificar qual profissional deveria se especializar em fraudes, apresentaram na sua pesquisa que o contador forense foi relacionado como o demandado em caso de combate e/ou investigação a fraude dentro das empresas e que a atuação deste profissional foi considerada como destacada em comparação com a de outros profissionais no ramo. Visto a semelhança, Prates, Souza e Salaberry (2018), levantaram no seu trabalho que peritos contábeis do SEAP desenvolvem algumas atividades típicas de perícia contábil e outras de contabilidade forense, bem como algumas comuns às duas áreas indicadas. Nessa miscelânea, os autores Aquino e Moniana (2017) tambem tentam distinguir a contabilidade Forense da Perícia Contábil, que em teoria, as duas áreas se baseiam na investigação para atestar a veracidade de fatos levados a questionamento. Com base no estudo, conclui-se que há muitas semelhanças entre o contador forense e o perito contábil nos quesitos de julgamento e zelo profissional. Nessa linha, Cardoso (2008) afirma que essas duas areas possuem pontos em comum especialmente com relação ao direito, visto que ambos são subsidiadas por decisões dos magistrados.

Sendo assim, o perito não atua proativamente da prevenção da fraude e se preocupa exclusivamente a responder os quesitos elaborados pelas partes e na mensuração do ato após a sua ocorrência. Dentre outras diferenças, salienta-se a sua atuação, sendo que a perícia contábil atua em processos judiciais e extrajudiciais, buscando irregularidades administrativas e contábeis, enquanto a "contabilidade forense" atua especificamente em situações em que houve

Revista Eletrônica do Alto Vale do Itajaí - REAVI, v.09, nº 15, p. 077-095, dez. 2020. ISSN: 23164190, DOI 10.5965/2316419009152020077 


\section{REAVI}

ou há existência de fraude, buscando informações financeiras em empresas públicas e privadas.

Visto isso, na visão de Weber, Flach e Laffin (2018) a Perícia Contábil, quanto à perícia criminal contábil, prevê a obtenção de provas, afim de atestar a veracidade de determinados fatos. Para tanto, ela constitui um conjunto de procedimento técnico-científicos que autorizam a instância decisória de elementos de prova que sejam necessários para subsidiar uma justa solução do litígio ou constatação de fato (CFC, 2015a). Desse modo, com a finalidade de distinguir as caracteristicas de cada profissão, elaborou-se a tabela 3:

Tabela 3. Diferenças entre Perícia Contábil, Perícia Criminal Contábil e Contabilidade Forense

\begin{tabular}{l|l|l|l}
\hline \multicolumn{1}{c|}{ Tipo } & \multicolumn{1}{|c|}{ Perícia Contábil } & \multicolumn{1}{c|}{ Perícia criminal contábil } & \multicolumn{1}{c}{ Contabilidade Forense } \\
\hline Realização & Peritos autônomos "ad hoc" & Estado e governo & $\begin{array}{l}\text { Empresa ou profissional } \\
\text { autônomo }\end{array}$ \\
\hline Objetivo & Apurar Fatos & Apurar fatos & Apurar fatos \\
\hline Requisitada & Durante o processo Judicial & Antes do processo judicial & Fraudado (vitimas) \\
\hline Foco & $\begin{array}{l}\text { Processo judicial e } \\
\text { extrajudicial }\end{array}$ & Judicial & $\begin{array}{l}\text { Processo Judicial e } \\
\text { Extrajudicial }\end{array}$ \\
\hline Periocidade & Eventual/ a qualquer tempo & Eventual/a qualquer momento & Eventual \\
\hline $\begin{array}{l}\text { Sujeito Ativo e } \\
\text { Passivo }\end{array}$ & Parte fraudadas (vitimas) & $\begin{array}{l}\text { Ministério Público, delegacias, } \\
\text { Policia Federal }\end{array}$ & Vítimas ou acusados \\
\hline Escopo & Quesitos & Quesitos & $\begin{array}{l}\text { Denuncia Requerida (ação } \\
\text { pena privativa) }\end{array}$ \\
\hline Tempo & Histórico & Histórico & Histórico/futuro \\
\hline Tipo & Detectivo & Detectivo & Detectivo/Preventivo \\
\hline Formação & Contador & $\begin{array}{l}\text { Contador, economista, } \\
\text { administrador, advogado }\end{array}$ & $\begin{array}{l}\text { Contador, direito, } \\
\text { Economista, administrador }\end{array}$ \\
\hline Regularização & NBC PP & $\begin{array}{l}\text { NBC PP, Direito Penal e } \\
\text { Financeiro }\end{array}$ & Não tem regulamentação \\
\hline Produto Final & Laudo & Laudo & Relatório \\
\hline
\end{tabular}

Fonte: Adaptado de Silva (2008), Weber, Flach e Laffin (2018) e elaborado pelos autores (2020).

Nesses moldes, a Tabela 3 apresenta as principais diferenças entre a perícia contábil e criminal e contabilidade forense. Observa-se que estas diferenças orientam qual area requisitar em casos de invetigação financeiras. Sendo assim, a forma de atuação, tempo e habilitação difere. Destaca-se entre as assimetrias a natureza do direito, momento de requisição pelo juiz, solicitante da requisição e a formação profissional.

\section{METÓDO DE PESQUISA}

Esta pesquisa se propõe a realizar estudo bibliométrico nos artigos encontrados sobre o tema Contabilidade Forense e Perícia Criminal Contábil, publicados em eventos ou revistas cientificas, disponíveis nas bases de dados entre os anos de 1999 até 2019. Quanto aos objetivos, preocupou-se em apresentar um panorama dos estudos científicos desenvolvidos acerca do tema, afim de identificar o conhecimento sobre a área, portanto, classifica-se quanto aos fins, como descritiva, uma vez que aponta correlações entre variáveis e evidencia características de uma população ou fenômeno (VERGARA, 2010 e GIL, 2008).

Trata-se de um estudo bibliométrico, que de acordo com Soares Picolli e Casagrande (2018) se caracteriza por ser desenvolvido a partir das informações obtidas de grandes bases de dados acessível ao público em geral e trazer relevâncias sobre o tema. Já os autores Guedes e Bordchiver tratam a Bibliometria como:

"[..] uma ferramenta estatística que permite mapear e gerar diferentes indicadores de tratamento e gestão da informação e do conhecimento,

Revista Eletrônica do Alto Vale do Itajaí - REAVI, v.09, nº 15, p. 077-095, dez. 2020. ISSN: 2316 4190, DOI 10.5965/2316419009152020077 


\section{REAVI}

especialmente em sistemas de informação e de comunicação científicos e tecnológicos, e de produtividade, necessários ao planejamento, avaliação e gestão da ciência e da tecnologia, de uma determinada comunidade científica ou país, afim de quantificar, descrever e prognosticar o processo de comunicação escrita (Guedes e Bordschiver, 2005).

Ademais, no que diz respeito à abordagem, o estudo teve caráter quanti-qualitativo, por aplicar estatística descritiva na análise de dados coletados e apresentar os resultados obtidos em tabelas e gráficos.

O método de pesquisa deste trabalho se inicia com as seguintes etapas: a) escolha do período temporal e número da amostra - completos, publicados em revistas científicas ou eventos nacionais, e que tenham sido publicados no período entre os anos de 1999 e 2019; b) escolha das bases de dados utilizadas para a coleta dos artigos - a busca de artigos foi realizada nas bases Spell, Scielo e Google Acadêmico, c) a utilização das palavras chaves "Perícia criminal contábil" e "Contabilidade Forense".

\section{ANÁLISE DOS RESULTADOS}

Para análise dos resultados, utilizou-se a análise bibliométrica com abordagem quantitativa, visto que segundo Soares, Picolli e Casagrande (2018)"'...] a origem do termo bibliométria deu- se pela junção do radical "biblion", do grego, livro, com o sufixo "metria", no grego, mensuração", para mapear e avaliar as publicações científicas com o auxílio do software Microsoft Excel. Assim, serão utilizados os seguintes indicadores bibliométricos: a quantidade de artigos, distribuição dos artigos nas revistas e congressos, incidência dos métodos apresentados, as palavras chaves e os autores que mais publicaram sobre a temática.

\subsection{ANÁLISE QUANTITATIVA}

Nesta seção é abordada a análise e a verificação dos resultados por meio dos dados coletados. Na base Spell foram encontrados 3 artigos, na base Scielo 0 e no Google Acadêmico 17 artigos, com as palavras chaves "Perícia Criminal Contábil" e "Contabilidade Forense", totalizando em 20 artigos encontrados.

\subsubsection{Evolução e quantidade de artigos publicados}

Nesta parte será apresentado a evolução temporal dos artigos no período de 1999 até 2019, evidenciados na tabela 4.

Tabela 4. Quantidade de artigos publicados

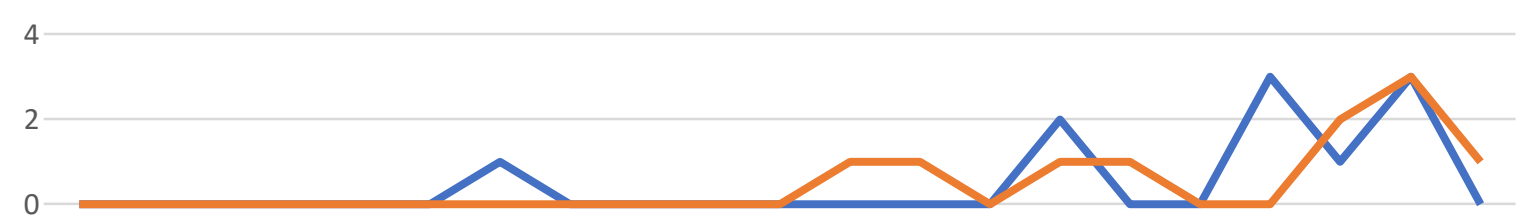

199920002001200220032004200520062007200820092010201120122013201420152016201720182019

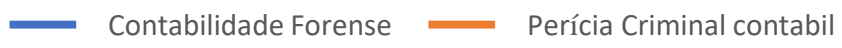

Fonte: Dados Pesquisados (2020).

Revista Eletrônica do Alto Vale do Itajaí - REAVI, v.09, nº 15, p. 077-095, dez. 2020. ISSN: 23164190, DOI 10.5965/2316419009152020077 


\section{REAVI}

Destaca-se pelo gráfico que houve crescimento da produção científica ao longo dos últimos 20 anos, ressaltando esse aumento no ano de 2013 com 1 artigo de perícia criminal contábil e 2 de contabilidade forense. Já em 2016 teve um aumento para 3 artigos de Contabilidade Forense, continuando esse crescimento em 2018, tendo 3 publicações tanto em Perícia Criminal Contábil como em Contabilidade Forense.

\subsubsection{Distribuição dos artigos pesquisados em periódicos}

A fim de estimar o grau de relevância dos periódicos, depreendeu-se da tabela 5, que são 10 os periódicos que publicaram sobre Perícia Criminal Contábil e Contabilidade Forense.

Tabela 5. Distribuição dos artigos pesquisados em periódicos

\begin{tabular}{lccc}
\hline Periódicos & F & $\%$ & $\begin{array}{c}\text { Qualis - } \\
\text { CAPES }\end{array}$ \\
\hline Revista de Gestão, Finanças e Contabilidade & 1 & $10 \%$ & $\mathrm{~B} 2$ \\
Organizações em contexto, São Bernardo do Campo & 1 & $10 \%$ & $\mathrm{~B} 1$ \\
Revista de Contabilidade do Mestrado em Ciências Contábeis da UER & 1 & $10 \%$ & $\mathrm{~A} 3$ \\
RAGC & 2 & $20 \%$ & $\mathrm{~B} 4$ \\
Revista de Educação e Pesquisa em Contabilidade & 2 & $20 \%$ & $\mathrm{~A} 2$ \\
Revista de Direito Internacional econômico e tributário & 1 & $10 \%$ & $\mathrm{~B} 1$ \\
Revista Brasileira de Criminalística & 1 & $10 \%$ & $\mathrm{C}$ \\
Revista Brasileira de Contabilidade & 1 & $10 \%$ & $\mathrm{C}$ \\
\hline Total & 10 & $100 \%$ & \\
\hline
\end{tabular}

Fonte: Dados Pesquisados (2020).

Dos 20 artigos analisados, $50 \%$ encontram-se no campo de revistas, sendo responsável por $20 \%$ das publicações as revistas RAGC e Revista de Educação e Pesquisa em Contabilidade. Já os demais periódicos disseminaram apenas 1 artigo relacionados às temáticas, entendendose que existe carência de produção e que essas áreas ainda são recentes na área da contabilidade.

\subsubsection{Nas distribuições de artigos em congressos}

Na distribuição de artigos em congressos, conforme a Tabela 7, são 10 os principais congressos que expandiram a produção científicas sobre a temática.

Tabela 6. Distribuição dos artigos em Congressos

\begin{tabular}{|c|c|c|}
\hline Congressos & $\mathbf{F}$ & $\%$ \\
\hline $\begin{array}{l}\text { Congresso USP iniciação cientifica em contabilidade e Internacional Conference in } \\
\text { Accounting }\end{array}$ & 4 & $40 \%$ \\
\hline Conferência Interamericana de Contabilidade & 1 & $10 \%$ \\
\hline Encontro de ensino e pesquisa em administração da Amazônia & 1 & $10 \%$ \\
\hline Congresso ANPCONT & 1 & $10 \%$ \\
\hline Cities in competition. XV Spanish-Portuguese Meeting of Scientific Management & 1 & $10 \%$ \\
\hline Congresso de Contabilidade e Auditoria & 1 & $10 \%$ \\
\hline Congresso UFSC & 1 & $10 \%$ \\
\hline Total & 10 & $100 \%$ \\
\hline
\end{tabular}

Fonte: Dados Pesquisados (2020).

Observa-se que dos 10 artigos publicados nos anais em congressos, 4 foram apresentados no Congresso USP, sendo referência em $40 \%$ nas produções sobre os temas. Da

Revista Eletrônica do Alto Vale do Itajaí - REAVI, v.09, nº 15, p. 077-095, dez. 2020. ISSN: 23164190, DOI 10.5965/2316419009152020077 


\section{REAVI}

mesma amostra, nos demais congressos apresentados na Tabela 6, publicaram 1 artigo nos últimos 20 anos.

\subsubsection{Incidência de metotologia}

Nesta divisão, por meio da Tabela 7, será exposto as metodologias usadas pelos autores, se os artigos publicados sobre as temáticas incidiam o método qualitativo, quantitativo ou qualiquanti.

Tabela 7. Incidência dos métodos aplicados

\begin{tabular}{lcc}
\hline Tipo de Método aplicado & Contagem & Frequência Relativa \\
\hline Qualitativo (sem estatística) & 11 & $55,0 \%$ \\
Quantitativo (com estatística) & 1 & $5,0 \%$ \\
Qualitativo e quantitativo (mix = quali-quanti) & 8 & $40,0 \%$ \\
\hline Total & 20 & $100 \%$ \\
\hline
\end{tabular}

Fonte: Dados Pesquisados (2020).

Em relação aos métodos de pesquisa utilizados nas pesquisas sobre o tema Contabilidade Forense e Perícia Criminal Contábil dos artigos analisados, o tema exigiu que a metodologia aplicada seja em 55\% sem estatística e $40 \%$ um mix com estatística e voltado para discussão e argumentação e 5\% quantitativo.

\subsubsection{Palavras-chave}

Com o auxílio do software Wordclouds se elaborou uma nuvem das palavras-chave utilizadas pelos autores dos artigos objeto desta pesquisa, conforme a figura 3 .

Figura 3. Nuvem de palavras-chave

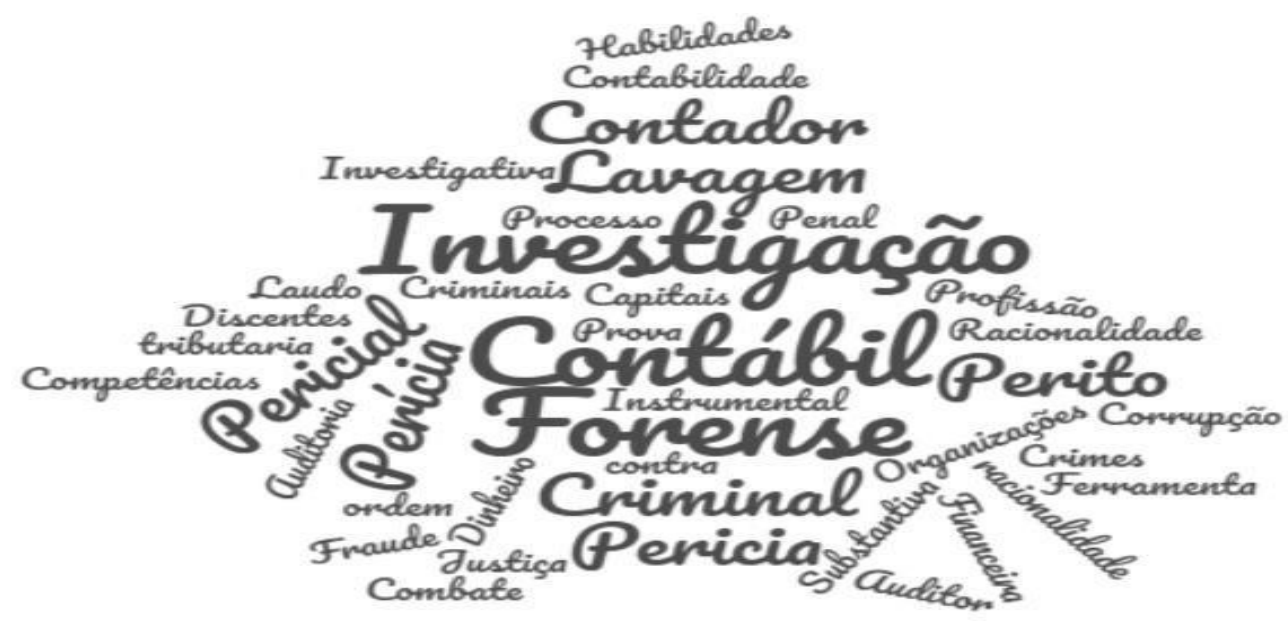

Fonte: Dados Pesquisados (2020).

Da análise dos termos mais usados destaca-se as palavras Contabilidade Forense com 23\%, fraude com 19\%, Organizações Criminais, Perícia Criminal Contábil com 16\% e Lavagem de Capitais com 10\% da amostra, totalizando 31 palavras-chaves encontradas.

Revista Eletrônica do Alto Vale do Itajaí - REAVI, v.09, n 15, p. 077-095, dez. 2020. ISSN: 23164190, DOI 10.5965/2316419009152020077 


\section{REAVI}

\subsubsection{Autores e publicações}

Na Tabela 8, será destacado os autores que mais contribuíram com a disseminação dos temas, responsáveis por contribuir ainda mais com a ciência contábil.

Tabela 8. Autores e artigos publicados

\begin{tabular}{lc}
\hline Autores & $\mathrm{N}^{\circ}$ de artigos \\
\hline Arnaldo Antônio Duarte Ribeiro & 2 \\
Raimundo Nonato Rodrigues & 2 \\
Idalberto José das Neves Júnior & 4 \\
\hline
\end{tabular}

Fonte: Dados Pesquisados (2020).

Dos artigos analisados, chegou-se a um total de 56 autores que publicaram sobre o tema Contabilidade Forense e Perícia Criminal Contábil e o autor que mais se destacou é Idalberto José das Neves com 4 artigos publicados. Vale ressaltar que o mesmo autor se destacou em outras pesquisas bibliográficas com o tema "Perícia Contábil".

\subsection{ANÁLISE QUALITATIVA DOS RESULTADOS}

Frente aos trabalhos encontrados na seção 4.1, identificou-se semelhanças nas fontes de pesquisas como de periódicos e congressos, tendo o predomínio da metodologia de caráter qualitativo e quali-quanti. Ademais, a média de artigos publicados sobre o tema "Perícia Criminal Contábil" foram de 11 artigos e 9 artigos em Contabilidade Forense.

A pesquisa intitulada "Perícia Contábil: Uma Ferramenta de Combate ao Crime Organizado" de Junior, Moreira (2011) é um dos mais citados, com 17 citações, por meio de questionário aplicado aos Delegados, Escrivães e Agentes de Polícia das divisões da Diretoria de Combate ao Crime organizado - DCOR do Departamento de Polícia Federal, traz uma visão sobre o crime organizado e sobre a petição da Perícia no respectivo orgão da Policia Federal. Ja o trabalho de Filho, Carlos e Costa (2017) com 6 citações, no mesmo cenario da Policia Federal, expoe as principais habilidades do perito criminal segundo a percepção dos peritos e delegados, chegando a conclusão que o "pensamento critico", "comunicação escrita" e "analise dedutiva" são as principais habilidades encontradas. Observou-se tambem a importancia da pesquisa de Ribeiro et., al (2016), com 9 citações encaminha percepções dos participantes do curso de combate a Lavagem de dinheiro do Ministerio da Justiça do Brasil, e com isso se depara com a necessidade de implementação de cursos de pos-graduação sobre Contabilidade Forense, alem de trazer conceitos sobre lavagem de capitais e de organizações criminosas.

Em relação aos autores, o Idalberto José nas Neves Junior também foi o que mais contribuiu em publicações sobre os temas Perícia Criminal Contábil e Contabilidade Forense. Os resultados mostram que quanto a perícia como a contabilidade forense e perícia criminal, são áreas de suma importância com avanços nos últimos anos, mas que ainda são poucas as publicações por serem assuntos poucos explorados e conhecidos pela sociedade e a classe contábil.

Outros autores como Aquino e Imoniana (2017) trouxeram questionamentos sobre as diferenças entre Perícia Contábil e Contabilidade Forense, e, com base na pesquisa, identificaram que as diferenças se encontram no escopo de atuação, sendo a Perícia Contábil mais abrangente do que a Contabilidade Forense, e respectivamente, apesar das duas estarem preocupadas com a apresentação de provas, uma tenha o foco de apresentar diante um órgão julgador e a outra a investigações judiciais e extrajudiciais, tanto para casos familiares ou privados. Cabe destacar também sobre a regularização no Brasil, a perícia é amplamente

Revista Eletrônica do Alto Vale do Itajaí - REAVI, v.09, nº 15, p. 077-095, dez. 2020. ISSN: 23164190, DOI 10.5965/2316419009152020077 


\section{REAVI}

regulada e a Contabilidade Forense não.

Autores como Ribeiro et. al (2016) concordam com Carneiro et., al (2016), Aquino e Imoniana (2017), Lucas e Relvas (2013), Ribeiro et. al (2013), Nadone et., al (2018), Prates, Souza e Salaberry (2018) ao identificar e apresentar as diferenças entre Auditoria, Perícia contábil e Contabilidade Forense na sua base teórica, dando relevância a essa diferenciação para a continuação da pesquisa e tirar as dúvidas aos leitores.

Já os autores Almeida e Taborda (2005) conduziram outra definição para a contabilidade forense, a "auditoria forense" (termo já utilizado em países como México, Espanha, Portugal, entre outros) afirmando que é a "disciplina que se baseia na contabilidade, auditoria e técnicas de investigação". Ainda há controvérsias sobre os conceitos. As competências do auditor forense, segundo autor é a técnica e experiência que lhes conferem credibilidade na prevenção e detecção de fraudes ao nível organizacional e também no desempenho de funções de perito em casos judiciais.

\section{CONCLUSÃO}

A pesquisa atingiu o objetivo que consistiu em evidenciar os artigos publicados sobre Contabilidade Forense e Perícia Criminal nos últimos 20 anos no Brasil, afim de elucidar conceitos sobre essas áreas que muitas vezes trazem dúvidas sobre a atuação e regulamentação no Brasil e se aplicou estatística descritiva na análise bibliométrica para salientar os resultados.

Curiosamente, os resultados indicam que são poucos autores que se aprofundam no tema com trabalhos publicados, porém, o conhecimento sobre as temáticas vem aumentando assim que acompanham a internacionalização da contabilidade com a adoção do IFRS.

Dada a importância da prova pericial criminal e da Contabilidade Forense, sobretudo quando conhecimentos tão específicos como a contabilidade estão relacionados, é importante avaliar a preocupação do poder público e da sociedade com a manutenção e formação de um corpo técnico de especialistas na área.

Entretanto, não se pode concluir que há pouco interesse por parte dos profissionais da Contabilidade, mas há desinformação sobre as áreas e sobre os termos, podendo haver diferenças em outros países.

Porém, no mercado empresarial, devido a uma demanda crescente, observa-se diversas ofertas de especializações de Pós-Graduação em Contabilidade forense e investigação em fraudes como em Perícia Criminal, demonstrando que o interesse vem aumentando assim que contadores vão formando opiniões e visões sobre o futuro da contabilidade como uma importante ferramenta contra a corrupção, erros e fraudes e que ainda ira ser muito debatida e avaliadas entre os profissionais da área.

Com base no estudo, se conseguiu identificar as semelhanças entre Perícia Criminal e Contabilidade Forense, sendo que ambas as áreas exigem senso crítico, olhar cético, conhecimento aprofundado sobre Contabilidade, aspectos jurídicos e graus de expertise, e as diferenças se centraram nos demandantes do trabalho, sendo a perícia criminal requisitadas exclusivamente pelos órgãos como MP, delegacias e Polícia federal por serem de origem penal e realizadas pelos institutos de criminalística como IGP e Polícia Federal. A Contabilidade Forense é requisitada por órgãos julgadores ou casos privados de origem cível, trabalhista, entre outros, ademais, se determina a encontrar o erro ou a fraude por meio de serviços de investigação, criminologia, técnicas contábeis com a resolução de problemas e serviços de litigação, já a perícia criminal contábil responde por meio do laudo aos questionamentos feitos pelas partes diante de um processo. Quanto a normatização, a Perícia Criminal Contábil, assim como a perícia contábil é amplamente regularizada pelo CRC, NBC e a Contabilidade Forense

Revista Eletrônica do Alto Vale do Itajaí - REAVI, v.09, no 15, p. 077-095, dez. 2020. ISSN: 23164190, DOI 10.5965/2316419009152020077 


\section{REAVI}

não possui nenhuma regularização no Brasil.

Sugere-se na área pedagógica a inserção de disciplinas de Contabilidade Forense e Perícia Criminal Contábil na graduação do curso de Ciências Contábeis, para que os discentes tenham noções mais específicas sobre fraudes e como elas surgem, para que dessa forma, quando se tornarem profissionais possam combater fraudes e fazer a prevenção de forma mais eficiente e consciente.

\section{REFERÊNCIAS}

AHMED, Sanjida; ALI, Mohobbot. FORENSIC ACCOUNTING: A CASE IN POINT FOR COMBATING FINANCIAL CRIMES OF BANGLADESH. International Journal of Accounting, v. 4, n. 23, p. 1-8, 2019.

ABDULRAHMAN, Mohammad Hassan Ali et al. The Impacto of Forensic Accounting on Fraud Detection in the UAE Banking Sector: A Study on Islamic and Conventional Banks. European Journal of Economic and Financial Research. 2020.

BARBOSA, Susana Isabel de Lage. O relato financeiro e a contabilidade forense. 2015 . Tese de Doutorado.

BRASIL. Lei n' 11.690, de 09 de junho de 2008. Brasília, DF, Disponível em: http://www.planalto.gov.br/ccivil_03/_Ato2007-2010/2008/Lei/L11690.htm

CARDOSO, FERNANDO NAZARETH. Contabilidade forense no Brasil: incipiência ou insipiência? Dissertação (Mestrado em Ciências Contábeis) - Programa Multi-institucional e Inter-Regional de Pós- graduação em Ciências Contábeis, Universidade de Brasília, Universidade Federal da Paraíba, Universidade Federal de Pernambuco, Universidade Federal do Rio Grande do Norte, 67. 2008.

CONSELHO FEDERAL DE CONTABILIDADE. Norma Brasileira de Contabilidade $\mathbf{n}^{\mathbf{0}}$ Técnica de Perícia, de 27 de fevereiro de 2015a. Dá nova redação à NBC TP 01. Perícia Contábil. Disponível em: http://www1.cfc.org.br/sisweb/SRE/docs/NBCTP01.pdf. Acesso em: 02 abr. 2018.

CRUMBLEY, D. Larry; SMITH, G. Stevenson. The games professors play in the dysfunctional performance evaluation system used in higher education: Brainstorming some recommendations. Higher education, p. 4, 2005.

DAS NEVES JÚNIOR, Idalberto José; DE SOUZA MOREIRA, Evandro Marcos. Perícia contábil: uma ferramenta de combate ao crime organizado. Revista de Educação e Pesquisa em Contabilidade (REPeC), v. 5, 2011.

DOS SANTOS FILHO, Carlos Roberto; CARLOS, Flávio Alves; DA COSTA, Fábio Moraes. Habilidades relevantes para a perícia contábil criminal: a percepção dos peritos e delegados da polícia federal. Revista de Educação e Pesquisa em Contabilidade, v. 11, n. 1, p. 69-89, 2017.

DE BRITO, Janaína Silva; DE MORAIS LUZ, Janayna Rodrigues; DE CARVALHO, José

Revista Eletrônica do Alto Vale do Itajaí - REAVI, v.09, nº 15, p. 077-095, dez. 2020. ISSN: 23164190, DOI 10.5965/2316419009152020077 


\section{REAVI}

Ribamar Marques. Perícia Contábil: Uma Análise Bibliométrica nos Principais Congressos Brasileiros de Contabilidade. Revista de Administração e Contabilidade da FAT, v. 9, n. 1, 2019.

DOS SANTOS SILVA, Ana Tereza et al. Uma análise bibliométrica nos periódicos QUALIS/CAPES: A produção científica sobre perícia contábil entre os anos de 2008 a 2019. RAGC, v. 8, n. 35, 2020

GRIPPO, Frank J.; IBEX, J. W. Introduction to forensic accounting. National Public Accountant, p. 4-5, 2003.

GUEDES, Vânia LS; BORSCHIVER, Suzana. Bibliometria: uma ferramenta estatística para a gestão da informação e do conhecimento, em sistemas de informação, de comunicação e de avaliação científica e tecnológica. Encontro Nacional de Ciência da Informação, v. 6, n. 1, p. $18,2005$.

IMONIANA, Joshua Onome; AQUINO, Aline Aparecida. Contabilidade Forense e Perícia Contábil: um estudo fenomenográfico. Revista Organizações em Contexto, v. 13, n. 26, p. 101-126, 2017.

LIMA, R. S.; GONÇALVES, A. O. Racionalidade substantiva em unidades de perícia criminal contábil-financeira. In: XII Congresso ANPCONT. 2018.

LUCCAS, Rudah Giasson; RELVAS, TÂNIA REGINA SORDI. O contador forense na investigação e no combate a fraudes no brasil: aplicação da técnica Delphi. XXXVII Encontro da ANPAD, 2013.

DAS NEVES JÚNIOR, Idalberto José; DE SOUZA MOREIRA, Evandro Marcos. Perícia contábil: uma ferramenta de combate ao crime organizado. Revista de Educação e Pesquisa em Contabilidade (REPeC), v. 5, 2011.

PANEL, PLANNING. Education and Training in Fraud and Forensic Accounting: A Guide for Educational Institutions, Stakeholder Organizations, Faculty, and Students, 2007.

PANIAGUA ARTAZKOZ, A. La auditoría forense como herramienta de prevención y detección del fraude. 33f. Trabalho de Conclusão de Curso - grado en contabilidad y finanzas - Universidad de la Laguna, 2018.

PASSINI, Simoni, PEREIRA L. L. Perícia Criminal Contábil - Conhecimentos, Informações e procedimentos. Trabalho de Conclusão de Curso - Curso de Ciências Contábeis, Universidade do Extremo Sul Catarinense. 2018.

RABUSKE, Rodrigo; BECKER, Laísa Ritiéle. Produção científica na área de perícia contábil: um estudo bibliométrico em periódicos listados pela QUALIS CAPES nos períodos de 2001 a 2018. Revista de Anais de Eventos Dom Alberto, v. 1(2), p. 43-51, 2019.

RIBEIRO, A. A. D., RODRIGUES, R. N., LAGIOIA, U. C. T., Castro, M. N. Contabilidade forense: Um estudo perceptivo na relevância da Contabilidade Forense na investigação de 


\section{REAVI}

lavagem de capitais praticadas por organizações Criminosas. Anais. In: Conferência Interamericana de Contabilidade, 30., Punta del Este, p. 2-3, 2013.

RIBEIRO, João Paulo Machado et al. Perfil Bibliométrico da Produção Científica sobre Perícia Contábil em Congressos Nacionais. Revista de Administração e Contabilidade-RAC, v. 6, n. 12, p. 73-86, 2019.

RIBEIRO, Arnaldo Antônio Duarte et al. Um estudo sobre a relevância da contabilidade forense como instrumento de investigação: a percepção de profissionais ligados ao combate à lavagem de capitais. Revista de Gestão, Finanças e Contabilidade, v. 6, n. 1, p. 45-75, 2016.

ROSA, M. J. F., LIMA, R. S. Associação Nacional dos Peritos Criminais Federais. Perícia Criminal Federal Contábil-Financeira. 2020. Disponível em: https://www.apcf.org.br/noticias/artigo-pericia-criminal-federal-contabil-financeira. Acesso em: 01 maio 2020.

SILVA, Thiago Henrique Costa. A perícia e o perito criminal contábil: Instrumentos a serviço da justiça. Revista Brasileira de Criminalística, v. 8, n. 1, p. 35-47, 2019.

SILVA, L. M. Contabilidade forense. In: Lopes, J., Ribeiro Filho, J. F., Pederneiras, M. (Org.). Educação contábil: tópicos de ensino e pesquisa, 2008.

SILVA, Robson Maciel da et al.Contabilidade forense no Brasil: uma proposição de metodologia. Dissertação de Mestrado, Universidade Presbiteriana Mackenzie, São Paulo, São Paulo, Brasil.

SILVEIRA, Cheila et al. A influência da perícia contábil nas decisões judiciais. Revista Scientia Plena, v. 9(11), 2013.

SKALAK, G. T. W.; CLAYTON, M.; P. A guide to forensic accounting investigation. John Wiley \& Sons. 2011.

SOARES, Sandro Vieira; PICOLLI, Icaro Roberto Azevedo; CASAGRANDE, Jacir Leonir. Pesquisa bibliográfica, pesquisa bibliométrica, artigo de revisão e ensaio teórico em administração e contabilidade. Administração: ensino e pesquisa, v. 19, n. 2, p. 1-19, 2018.

SCHMITZ, Tatiane et al. Perícia contábil: análise bibliométrica e sociométrica em periódicos e congressos nacionais no período de 2007 a 2011. Revista Catarinense da Ciência Contábil, v. 12, n. 37, p. 64-79, 2013.

SOUZA, R. B. L.; PRATES, ARIEL. Aspectos da produção científica nacional em Perícia Contábil entre 1999 e 2016: análise bibliométrica de artigos publicados nos principais periódicos e anais de congressos. In: Anais do Congresso USP de Controladoria e Contabilidade. 2017.

VERGARA, Sylvia Constant. Projetos e Relatórios de Pesquisa em Administração Editora Atlas S. A São Paulo, p. 43, 2010. 


\section{REAVI}

WEBER, Bruna Benita Sanchez Lopez; FLACH, Leonardo; LAFFIN, Nathália. Fraudes e perícia criminal contábil: análise dos laudos periciais de Santa Catarina. Revista de Auditoria Governança e Contabilidade, v. 6(25), 2018. 